\title{
COMUNICACÕES
}

\section{Sensibilidade de isolados de Phakopsora pachyrhizi provenientes da região do centro oeste do Paraná a fungicidas}

\author{
Eduard Duhatschek ${ }^{1}$, Leandro Alvarenga Santos ${ }^{1}$, Cacilda Márcia Duarte Rios Faria ${ }^{1}$
}

\begin{abstract}
${ }^{1}$ Universidade Estadual do Centro Oeste - UNICENTRO, Departamento de Agronomia, 85040-080, Paraná, PR, Brasil.
Autor para correspondência: Leandro Alvarenga Santos (leandro.alvarenga.s@hotmail.com)

Data de chegada: 14/02/2017. Aceito para publicação em: 14/08/2017.
\end{abstract}

$10.1590 / 0100-5405 / 175840$

Um dos principais fatores que reduzem a produtividade da cultura da soja no Brasil são as doenças. A principal doença da cultura é a ferrugem asiática causada por Phakopsora pachyrhizi Sydow e Sydow. O último levantamento do custo do controle da ferrugem no Brasil, considerando as reduções em produtividade e o custo do controle da doença, foi estimado em U\$ 2,2 bilhões por safra (3). O controle eficiente desta doença envolve várias medidas integradas, como plantio de cultivares com ciclo precoce, implantação do vazio sanitário e aplicação de fungicidas protetores e penetrantes móveis. Embora haja um grande número de produtos comerciais registrados para controle da ferrugem asiática no Brasil, pertencem apenas a três mecanismos de ação. Nos últimos anos tornaram-se frequentes relatos de produtos com eficiência reduzida, devido a isto em 2016 com base na Portaria n 9 91, 2105/2015, o ADAPAR (1) suspendeu a comercialização no estado do Paraná de 67 fungicidas por baixa eficiência no controle da ferrugem asiática (2).

Diante deste cenário, pesquisas que visem o monitoramento da sensibilidade do patógeno da ferrugem asiática da soja tornam-se imprescindíveis. Portanto, o objetivo deste trabalho foi verificar o efeito de aplicações de fungicidas em áreas comerciais na sensibilidade de isolados de $P$. pachyrhizi, proveniente de cinco localidades da região de Centro Oeste do Paraná.

Os isolados de P. pachyrhizi foram obtidos de lavouras comerciais, sendo provenientes de quatro cultivares e tratadas com diferentes ingredientes ativos antes da coleta (Tabela 1).

Após a coleta, foi obtida uma suspensão de esporos $\left(2 \times 10^{4}\right.$ conídios $\mathrm{mL}^{-1}$ ) utilizada no teste de germinação. $\mathrm{O}$ teste foi realizado pelo método da placa de Elisa. As placas foram mantidas em BOD, com fotoperíodo de 12 horas e temperatura de $25^{\circ} \mathrm{C}$. A germinação foi paralisada 24 horas após, utilizando $20 \mu \mathrm{L}$ do corante azul algodão de lactofenol. Foram avaliados 100 esporos em duplicata, estabelecendo o percentual de esporos germinados.

O delineamento utilizado foi o de blocos casualisados, com cinco tratamentos, compostos por cinco diferentes dosagens de dois fungicidas, piraclostrobina + epoxiconazol $\left(\right.$ Opera $\left.^{\circledR}\right)$ e trifloxistrobina + protioconazol $\left(\right.$ Fox $\left.^{\circledR}\right)$, com 5 repetições. As dosagens utilizadas para o produto piraclostrobina + epoxiconazol foram $332 \mathrm{mg} / \mathrm{L}+$ $125 \mathrm{mg} / \mathrm{L} ; 33,2 \mathrm{mg} / \mathrm{L}+12,5 \mathrm{mg} / \mathrm{L} ; 3,32 \mathrm{mg} / \mathrm{L}+1,25 \mathrm{mg} / \mathrm{L} ; 0,332 \mathrm{mg} / \mathrm{L}$ $+0,125 \mathrm{mg} / \mathrm{L} ; 0,0332 \mathrm{mg} / \mathrm{L}+0,0125 \mathrm{mg} / \mathrm{L}$. Para o produto trifloxtrobina + protioconazol as dosagens utilizadas foram $225 \mathrm{mg} / \mathrm{L}+262,5 \mathrm{mg} / \mathrm{L}$; $22,5 \mathrm{mg} / \mathrm{L}+26,25 \mathrm{mg} / \mathrm{L} ; 2,25 \mathrm{mg} / \mathrm{L}+2,625 \mathrm{mg} / \mathrm{L} ; 0,225 \mathrm{mg} / \mathrm{L}+$ $0,2625 \mathrm{mg} / \mathrm{L} ; 0,0225 \mathrm{mg} / \mathrm{L}+0,02625 \mathrm{mg} / \mathrm{L}$, respectivamente.

Os dados foram submetidos à análise de variância e as médias submetidas a regressão polinomial. Posteriormente foram calculadas a concentração inibitória de $50 \%\left(\mathrm{IC}_{50}\right)$ e a concentração inibitória máxima (CIM).

Todos os isolados apresentaram redução da germinação de esporos pelo aumento da concentração dos fungicidas. Para o fungicida a base de piraclostrobina + epoxiconazol, os isolados da região centro oeste do Paraná não apresentaram diferença para a $\mathrm{IC}_{50}$.

Entretanto para a CIM, os isolados provenientes do Xarquinho e Campina do Simão apresentaram menor valor de CIM, indicando alta sensibilidade ao fungicida, ambos os isolados foram obtidos de plantas da cultivar Ni6202, onde foram realizadas pulverizações com trifloxistrobina + protioconazol (Figura 1).

A sensibilidade de produtos à base de piraclostrobina já foi determinada por REIS et al. (6), utilizando triazóis e estrobilurinas, demonstraram a ocorrência da redução da sensibilidade de $P$. pachyrhizi ao fungicidas a base de tebuconazol, porém não se detectou alteração na sensibilidade do fungo à piraclostrobina.

A IC $_{50}$ da trifloxistrobina + protioconazol, para os isolados de P. pachyrhizi apresentou diferença, os isolados de Manoel Ribas e Xarquinho tiveram os valores de $\mathrm{IC}_{50}$, mais elevados (acima de $100 \mathrm{~mL} /$ ha), ambos locais possuem histórico de aplicações com fungicidas com os mesmos ingredientes ativo, demonstrando redução da sensibilidade por exposição a esses ingredientes ativos (5).

$\mathrm{Na} \mathrm{CIM}$, apenas o isolado de Boa Esperança apresentou valor inferior aos demais, uma possível explicação é a utilização de fungicidas

Tabela 1. Origem dos isolado, locais de origem, cultivares e fungicidas (nome técnico e comercial) aplicados na área

\begin{tabular}{|c|c|c|c|}
\hline Isolado & Coordenada geográfica & Cultivar & Fungicida aplicado \\
\hline Boa Esperança & $24^{\circ} 14^{\prime} 39.3 ” \mathrm{~S} 52^{\circ} 47^{\prime} 30.3^{\prime \prime} \mathrm{W}$ & Syngenta 1163 & Ciproconazol e picoxistrobina (APROACH PRIMA ${ }^{\circledR}$ ) \\
\hline CEDETEG & $25^{\circ} 23^{\prime} 02.5^{\prime \prime} \mathrm{S} 51^{\circ} 29^{\prime} 30.2^{\prime \prime} \mathrm{W}$ & BMX Apolo RR & Sem aplicações \\
\hline Xarquinho & $25^{\circ} 21^{\prime} 47.6^{\prime \prime S} 51^{\circ} 30^{\prime} 13.3^{\prime \prime} \mathrm{W}$ & Ni 6202 & Trifloxistrobina e protioconazol $\left(\mathrm{FOX}^{\circledR}\right)$ \\
\hline Campina do Simão & $25^{\circ} 06^{\prime} 27.6^{\prime \prime} \mathrm{S} 51^{\circ} 48^{\prime} 14.0^{\prime \prime} \mathrm{W}$ & Ni 6202 & Trifloxistrobina e protioconazol $\left(\mathrm{FOX}^{\circledR}\right)$ \\
\hline
\end{tabular}


$\mathrm{IC}_{50}$ - Trifloxystrobina e Protioconazol

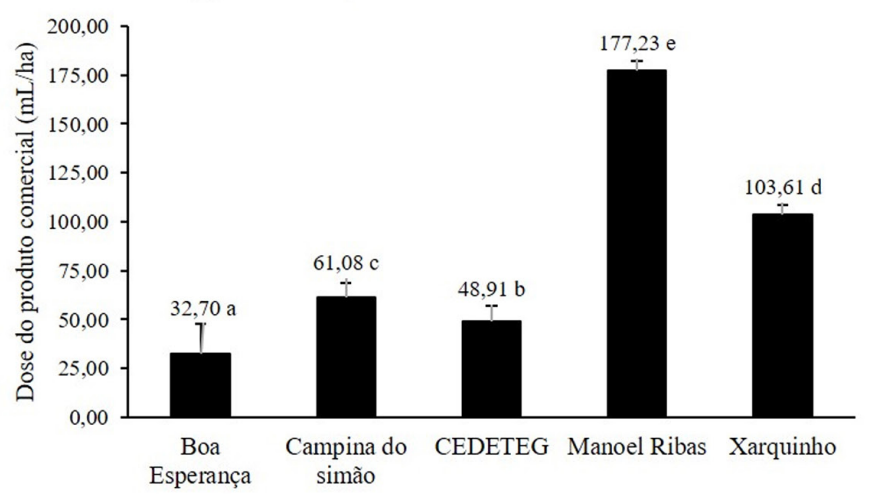

$\mathrm{IC}_{50}$ - Piraclostrobina + Epoxiconazol

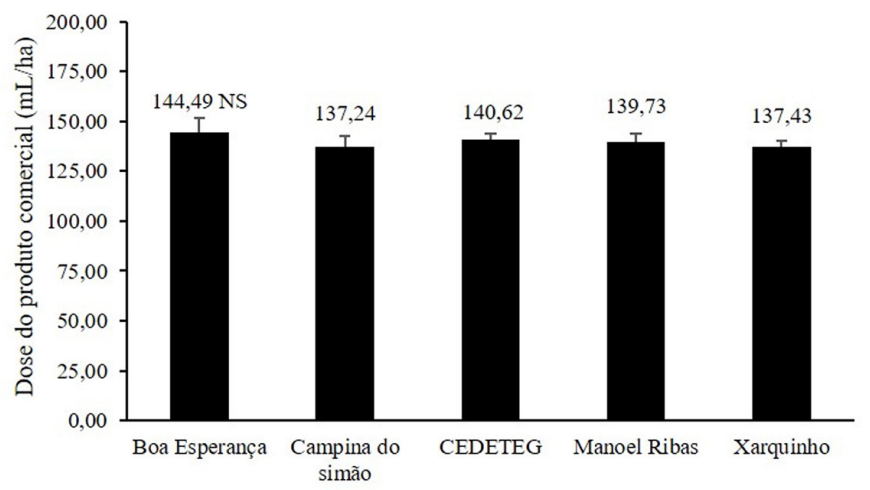

CIM - Trifloxystrobina e Protioconazol

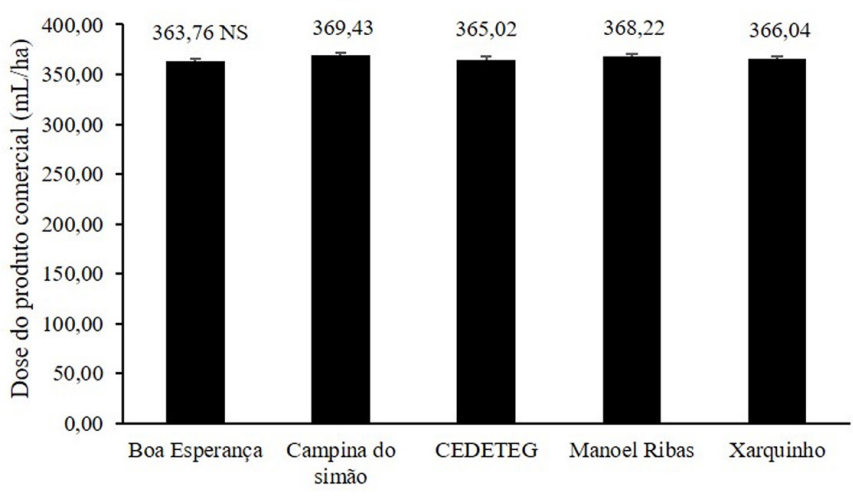

CIM- Piraclostrobina +Epoxiconazol

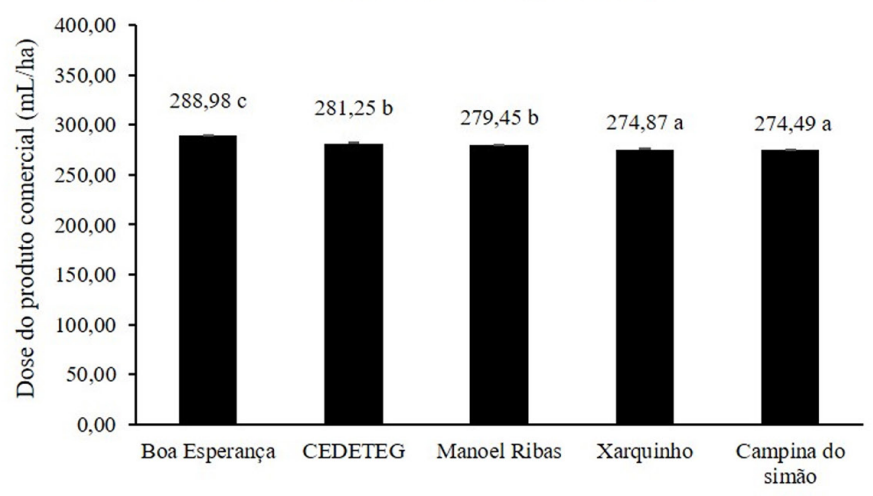

Figura 1. Concentração inibitória de $50 \%$ da germinação de esporos $\left(\mathrm{CI}_{50}\right)$ e concentração mínima inibitória (CMI) das misturas de fungicidas piraclostrobina + epoxiconazol e de trifloxistrobina + protioconazol a cinco isolados de Phakopsora pachyrhizi.

Ns - Não significativo pela ANOVA.

Médias seguidas de mesma letra não diferem entre si, pelo teste de scott knott a 5\% de probabilidade.

com outros ingredientes ativos no controle desta área diferentes dos testados. Os demais locais não diferiram estatisticamente. Constatouse que áreas com histórico de aplicações de Trifloxistrobina + Protioconazol proveram isolados menos sensíveis ao produto, quando comparado aos isolados de áreas que foram conduzidas com outros produtos. Os isolados coletados na cultivar Ni6202 e tratados com trifloxistrobina + protioconazol, apresentaram maior sensibilidade a piraclostrobina + epoxiconazol em comparação aos demais, demonstrando o efeito benéfico da rotação de princípios ativos no controle da ferrugem asiática.

Moura et al. (4) obteve valores da $\mathrm{IC}_{50}$ de oito fungicidas para o controle de $P$. pachyrhizi de diferentes locais, dentre os tratamentos utilizados, piraclostrobina e a mistura trifloxistrobina + protioconazol obtiveram os menores valores da $\mathrm{IC}_{50}$, e a mistura piraclostrobina + epoxiconazol teve valores mais elevados. Em todos estes trabalhos não foi investigado a área em que os isolados foram obtidos e a quais ativos o patógeno havia sido exposto.

Portanto se pode concluir que as áreas tratadas com trifloxistrobina + protioconazol, apresentaram redução da sensibilidade ao produto. Tornando assim notória a necessidade da rotação de ingredientes ativos, de modo a evitar a seleção de indivíduos resistentes.

\section{REFERÊNCIAS}

1. ADAPAR - Agência de Defesa Agropecuária do Paraná. Lista de Agrotóxicos aptos para comércio e uso no Paraná. Disponível em: <www.adapar.pr.gov. br/> Acesso em: 20 de jan. 2017.

2. AGROLINK. Paraná suspende 67 defensivos com baixa eficiência contra ferrugem asiática. Disponível em: <https://www.agrolink.com.br/noticias/ parana-suspende-67-defensivos-com-baixa-eficiencia-contra-ferrugem-asiatica_350847.html.>Acesso em: 20 jan. 2017

3. CONSÓRCIO ANTIFERRUGEM. Conheça a ferrugem: Tabela de custo. Disponível em: Disponível em:<http://www.consorcioantiferrugem.net/> Acesso em: 20 de jan. 2017.

4. MOURA, Bianca; BOLLER, Walter; DEUNER, Carolina Cardoso. In vitro Determination of Fungicide Inhibitory Concentration for Phakopsora pachyrhizi isolates. Summa Phytopathologica, v. 42, n. 2, p. 170-171, 2016.

5. OLIVEIRA, S. C.; CASTROAGUDÍN, V. L; MACIEL, J. L. N.; PEREIRA, D A. S.; CERESINI, P. C. Resistência cruzada aos fungicidas IQo azoxistrobina e piraclostrobina no patógeno da brusone do trigo Pyricularia oryzae no Brasil. Summa Phytopathologica, v. 41, n. 3, p. 298-304, 2015. 6. REIS, ERLEI MELO; DEUNER, ELAINE; ZANATTA, MATEUS. In vivo sensitivity of Phakopsora pachyrhizi to DMI and QoI fungicides. Summa Phytopathologica, v. 41, n. 1, p. 21-24, 2015. 